Vitulia Ivone. Profesora de Derecho Privado, Dipartimento di Scienze giuridiche de la Università degli Studi di Salerno. Ha sido profesora de Derecho Civil en la Escuela de Profesiones Legales; dirije el Comité científico de la Fundación de la Scuola Medica Salernitana. Forma parte del comité académico del Doctorado en Ciencias Jurídicas, de la Comisión de las Patentes de la Università di Salerno, del Observatorio de Derechos Humanos: bioética, salud y medio ambiente, del comité científico de la revista Biodiritto (Aracne Roma) y de los Cuadernos de Bioética (UMSA, Buenos Aires). También es co-directora de la Escuela Internacional de Bioética y Salud 2015, Università di Salerno.

Contacto: vituliaivone@unisa.it 


\section{“THE RIGHT TO RELATE AND THE SEXUAL ORIENTATION": \\ EL DERECHO A UNA VIDA PRIVADA}

Vitulia Ivone

Università di Salerno

“THE RIGHT TO RELATE AND

THE SEXUAL ORIENTATION": THE RIGHT TO A PRIVATE LIFE

DOI: $10.17450 / 150212$

Fecha de recepción 13 de agosto 2015; fecha de aceptación 9 de octubre 2015. El artículo es fruto de un proyecto de investigación desarrollado en el Dipartimento di Scienze Giuridiche de la Università degli Studi di Salerno.

\section{Resumen}

En 1976, por primera vez, la Comisión Europea de Derechos Humanos apoyó el derecho a establecer relaciones con otros seres humanos como una cuestión de respeto de la vida privada. Hablar de right to relate significa considerar todos los asuntos relacionados con el derecho a la orientación sexual. El tema del matrimonio entre personas del mismo sexo se cuestiona de forma diferente en Europa y en Italia: tras algunas decisiones de los Tribunales italianos y la condena de la CEDH -que reconoció la violación del Estado italiano del derecho a la vida privada y familiar de gays, lesbianas y bisexuales- el Parlamento italiano ha empezado a reflexionar. 


\section{Palabras clave}

Subjetividad, relación emocional, orientación sexual.

\section{Abstract}

The right to establish and develop relationships with other human beings was first articulated by the European Commission of Human Rights. Thinking about 'the right to relate' it means to consider the link that unites all matters relating to the right to sexual orientation. The issue of same-sex marriage have different responses in Europe and Italy: after some decisions of the Italian courts and after sentence by the ECHR - which recognized the violation by the Italian State the right to private and family life of gays, lesbians and bisexuals - start time reflections to the Parliament in Italy.

\section{Keywords}

Subjectivity, emotional relationship, sexual orientation.

\section{Consideraciones preliminares}

Para el derecho, es difícil hablar de "derecho a relacionarse" sin considerar la orientación sexual. La orientación sexual es la atracción afectiva y sexual hacia una persona, e incluye tanto una parte emocional (conjunto de sentimientos y preferencias) como una parte de conducta sexual (conjunto de prácticas y actos sexuales). Se habla de orientación heterosexual cuando la atracción se dirije a una persona del sexo opuesto, de orientación homosexual cuando la atracción está abierta a personas del mismo sexo y de orientación bisexual cuando la atracción se dirije tanto a personas del mismo sexo, como a personas del sexo opuesto. La orientación sexual no es dicotómica, sino se extiende a lo largo de un continuum que va del heterosexual exclusivo al homosexual exclusivo, a través de etapas intermedias que empujan hacia un polo u otro, y que algunas veces tienen actitudes contrarias.

La identidad sexual se compone de cuatro elementos distintos: el sexo biológico, la identidad de género, el rol de género y la orientación sexual.

El sexo biológico es la relación biológica con el sexo masculino o femenino que está determinada por los cromosomas sexuales. 
La identidad de género indica el persistente sentido de sí mismo como hombre o mujer, es la percepción de su propia masculinidad o feminidad, y parece ser una característica estable de la personalidad y de la conciencia que se remonta a la infancia.

En cambio, el rol de género es lo que una persona dice o hace para explicarse a sí mismo y a otros su grado de masculinidad o feminidad, y por lo tanto es la expresión exterior de la identidad de género, que refleja los estereotipos dominantes en una determinada cultura, sociedad y período histórico.

El art. 8 de la Convención Europea de Derechos Humanos habla del derecho al respeto de la vida privada -incluido el derecho a una vida personal y a establecer y desarrollar relaciones con otros seres humanos-, del derecho a establecer y desarrollar relaciones en el ámbito familiar y no familiar -incluidas las de tipo "profesional o empresarial"-, del derecho al respeto de la vida específicamente familiar -que incluye las relaciones matrimoniales y las relaciones con los hijos, así como las uniones no matrimoniales-y del derecho al respeto de la vida familiar en las parejas de sexo opuesto y del mismo sexo.

La relación afectiva homosexual, por lo que a la expectativa social de dualismo y la complementariedad entre hombres y mujeres se refiere -regla general y que fundamenta el género-, implica que nos interroguemos acerca de las cuestiones básicas y más íntimas de nuestra identidad personal.

¿Cómo contestar correctamente a la pregunta acerca de la posibilidad de elegir como cónyuge a una persona del mismo sexo?

Y el derecho, ¿cómo contesta cuándo a una tradición que lleva aceptando desde hace mucho tiempo el paradigma heterosexual como algo específico del matrimonio, sin ni siquiera saber por qué, se oponen personas que desafían este paradigma en sus vidas y en la ley?

Estas preguntas se refieren a los ejes más profundos de la experiencia humana, a todas las imágenes que asociamos con el afecto, las raíces, el amor, el sexo, la mirada hacia el futuro, las experiencias - positivas y negativas- de la gratuidad de las relaciones afectivas y el don de amor típicamente asociado con la familia.

Por lo tanto, el tema del matrimonio entre personas del mismo sexo plantea un problema muy complejo: la relación entre el principio de la igualdad formal-dintel de nuestra civilización- y la noción tradicional de familia heterosexual, que también es un principio muy antiguo.

En particular, en este trabajo pretendemos reflexionar sobre las parejas del mismo sexo, es decir, sobre uno de los topos más estudiados por el derecho europeo en los últimos tiempos, sobre todo por la CEDH. 
La interpretación cada vez más amplia de la evolución propuesta por el Tribunal de Estrasburgo a las disposiciones de la Convención sobre los derechos personales y la prohibición de la discriminación, la Directiva 2000/78 CE relativa a la igualdad de trato en el empleo y en las condiciones de trabajo, y la entrada en vigor de la Carta de Niza han ampliado considerablemente los ámbitos de igualdad de las parejas homosexuales o del individuo homosexual y de los heterosexuales.

\section{El respeto de la vida privada en la CEDH}

Los arts. 8 y 14 de la CEDH proponen el derecho a una vida privada y familiar ${ }^{1} \mathrm{y}$, para que este derecho pueda ser ejercido, también la prohibición de la discriminación, incluyendo el sexo.

Los mismos principios se hallan en los arts. 7 y 21 de la Carta de Niza: en particular, el art. 21 incluye explícitamente en los ámbitos en que la discriminación está prohibida no solo el sexo, sino también la orientación sexual. Esto se debe a que el Tribunal de Derechos Humanos nunca había considerado completa la lista de casos presentes en el art. 14 y había aplicado esta regla a los casos de discriminación por homosexualidad. Sin embargo, la ampliación prevista en el art. 21 destaca una mayor sensibilidad hacia el problema ${ }^{2}$.

La CEDH ya había dicho que -a raíz del art. 8 de la CEDH, que tiene el objetivo de proteger a las personas contra la interferencia injustificada de las autoridades públicaslos Estados miembros tienen que respetar la vida familiar, adoptando todas las medidas prácticas para garantizarles a los individuos el goce de los derechos previstos por el art. 8 .

A este respecto, cabe señalar dos casos significativos: en el primero ${ }^{3}$, los jueces de Estrasburgo aceptaron un recurso de apelación relativo a la discriminación de una pareja

1. C. Pitea, L. Tomasi, “Commentario breve alla Convenzione europea dei diritti dell'uomo”, Art. 8, S. Bartole, P. De Sena, V. Zagrebelsky (eds.), Padova, 2012, pp. 297 ss.; A. Di Stasi, “The Inter-American Court of Human Rights and the European Court of Human Rights: Towards a 'Cross Fertilization?”, en Ordine internazionale dei diritti umani, 1, 2014; S. Negri, "El consentimiento informado en la jurisprudencia del Tribunal Europeo de Derechos Humanos”, en Julgar, n.e., 2014.

2. El principio de igualdad de trato $-\mathrm{y}$ la prohibición de la discriminación de los homosexuales en el empleo y en las condiciones de trabajo- ya había sido tomado en consideración por la Unión Europea en una Directiva (27 de noviembre de 2000/78/ce) con la cual la UE quiso establecer un marco general para luchar contra la discriminación por motivos de religión o convicciones, discapacidad, edad u orientación sexual, en el ámbito del empleo y las condiciones de trabajo con el fin de llegar a practicar, en los Estados miembros, el principio de igualdad de trato. Con esta Directiva se proclamó rigurosamente el principio de igualdad de trato, y también la prohibición de la discriminación de los homosexuales en el empleo y en todas las condiciones de trabajo. La jurisprudencia del Parlamento Europeo también impuso a los Estados reconocer las convivencias y los matrimonios entre personas del mismo sexo.

3. Corte EDU, Karner v. Austria (ric. n. 40016/98). 
del mismo sexo, señalando que la retirada del reconocimiento del derecho de sucesión de la persona superviviente de la pareja violaba el art. 14 de la CEDH, con relación al art. 8, ya que este derecho parecía garantizado por la legislación del Estado demandado y la diferencia de trato dependía exclusivamente de la orientación sexual de la pareja. En esa ocasión, también la Corte sostuvo que la protección del matrimonio tradicional no justifica la exclusión de las parejas del mismo sexo de los derechos reconocidos a las heterosexuales no casadas, pero subrayó que no es necesario especificar las nociones de "vida privada" y “vida familiar", puesto que el caso podría resolverse haciendo referencia al "derecho de residencia", que también está protegido por el art. 8 de la Convención".

En otras palabras, señalando la rápida evolución social de los últimos años en gran parte de los Estados miembros de la Convención para el reconocimiento legal de las parejas del mismo sexo a raíz de lo dispuesto por el Derecho de la Unión Europea que refleja esta tendencia a incluir a las parejas homosexuales en el ámbito de la familia, por primera vez la Corte reconocía "the relationship of the applicants, a cohabiting same-sex couple living in a stable de facto partnership, falls within the notion of 'family life', just as the relationship of a different-sex couple in the same situation would".

En el segundo caso ${ }^{5}$, notando la cada vez más frecuente tendencia de los países miembros del Consejo de Europa a reconocer legalmente las uniones entre personas del mismo sexo, y rompiendo con la política anterior, la Corte EDU sostuvo que estas relaciones emocionales se deben considerar formas de "vida familiar", conformemente al art. 8 de la CEDH. Para los jueces de Estrasburgo, tras todos los avances sociales, sería inadecuado decir que, a diferencia de una pareja heterosexual, una pareja homosexual no puede gozar de la "vida familiar" del art. 8. De hecho, las parejas del mismo sexo -tal como las heterosexuales- pueden tener relaciones estables y hacerse cargo de los relativos compromisos; por consiguiente, necesitan que se reconozcan y protejan sus relaciones. La redefinición de la noción de "vida familiar” que incluye también a las parejas del

\footnotetext{
4. L. Magi, "La Corte europea dei diritti dell'uomo e il diritto alla vita familiare e al matrimonio fra individui dello stesso sesso", en Rivista di diritto internazionale, 2011, pp. 396 ss.; C. Rimini, "L'affidamento familiare ad una coppia omosessuale: il diritto del minore ad una famiglia e la molteplicità dei modelli familiari”, en Il Corriere Giuridico, 2, 2014; A. Schillaci, Omosessualità, eguaglianza, diritti, Carocci, Roma, 2014; L. Morassutto - M. Winkler, "Le tante facce dell'omofobia: una sentenza recente della Corte di Giustizia dell'UE in materia di rifugiati omosessuali”, en Nuova giur.civ.comm., 6, 2014 ; M. G. Ruo, "A proposito di genitorialità adottiva e interesse del minore", en Fam. e dir., 6, 2015.

5. Corte Europea de Derechos Humanos, Schalk y Kopf c. Austria, recurso n. 30141/04, sentencia del 24 de junio de 2010, pár. 94. C. Ragni, "La tutela delle coppie omosessuali nella recente giurisprudenza della Corte europea dei diritti umani: il caso Schalk e Kopf", en Diritti umani e diritto internazionale, 2010, pp. 639 ss.; M. Winkler, "Le famiglie omosessuali nuovamente alla prova della Corte di Strasburgo", en Nuova giurisprudenza civile commentata, 2010, vol. 1, pp. 1148 ss; V. Scalisi, “Pluralizzazione' e 'riconoscimento' anche in prospettiva europea”, en Riv.dir.civ., 6, 2013; M. Segni, "Matrimonio omosessuale: novità dall'Europa”, en Fam. e dir., 7, 2014; L. Attademo, "L'interesse del minore a frequentare il genitore sociale omosessuale", en Giur.it., 6, 2015. Véase también Corte Europea de Derechos Humanos, P.B. y J.S. c. Austria, recurso n. 18984/02, sentencia del 22 julio de 2010, pár. 30.
} 
mismo sexo ha sido un pasaje importante de la protección otorgada por la CEDH en estos informes. De hecho, el derecho a la vida familiar ofrece una protección más amplia, incluyendo el derecho de los miembros de la familia a vivir juntos, la obligación de los Estados miembros a adoptar políticas que protejan a la familia, incluyendo la previsión de beneficios sociales y económicos. El hecho de que las parejas del mismo sexo pueden gozar de la vida familiar en virtud del art. 8 de la CEDH ha sido -sin lugar a dudas- el requisito previo para llegar a la reconstrucción de la obligación positiva que hoy se exige a Italia, pues introducir en su sistema un marco legal específico para el reconocimiento de las uniones de personas del mismo sexo.

Es importante recordar también que, en 2013, el Tribunal de Derechos Humanos condenó a Grecia por haber violado el art. 14 de la CEDH, relacionado con el art. 8 de la misma, teniendo en cuenta que la introducción de una ley de uniones civiles relativa a las parejas de distinto sexo, se traduciría en una diferencia de trato entre las parejas heterosexuales y las homosexuales, y constituiría una discriminación injustificada basada en la orientación sexual ${ }^{6}$.

En este contexto, la Corte no se limita a señalar que las relaciones entre las parejas de los solicitantes recaen en la esfera de la vida familiar, sino extiende la noción de "vida familiar" para incluir también las parejas homosexuales estables que, por razones profesionales o sociales, no conviven.

Recurriendo a la llamada "interpretación evolutiva", los jueces de Estrasburgo recuerdan que la Convención se debe interpretar como un derecho vivo; por consiguiente, a la hora de elegir las medidas de protección a la familia, el Estado tiene que tomar en cuenta la evolución y los cambios sociales, ya que no hay una sola forma de pensar en la familia ${ }^{7}$.

\section{La Resolución del Parlamento Europeo del 4 de febrero de 2014}

Con una resolución del 4 de febrero de 2014, el Parlamento europeo destacó que no se respetaban plenamente los derechos fundamentales de la UE de las personas LGBT. De ahí que el Parlamento pidiera a la Comisión, a los Estados miembros y a las agencias europeas que trabajaran juntos para una "política global”, esto es, un plan estratégico

6. Caso Vallianatos and Others v. Greece de 2013.

7. D. Duran, "Unioni civili registrate e discriminazione fondata sull'orientamento sessuale: il caso Vallianatos", en Diritti umani e diritto internazionale, n. 8, 2014, p. 234. 
para garantizar la plena protección de estos derechos, sobre todo la libertad de circulación de los ciudadanos de la UE con la finalidad de garantizar el funcionamiento de todas las formas de familia reconocidas legalmente por las leyes nacionales de los Estados miembros. Sin embargo, por lo que a la educación se refiere, el Parlamento pedía un fortalecimiento de las políticas contra la intimidación y la discriminación sexual. Además, recomendaba que se adoptaran medidas para reconocer legalmente el género y se respetara el derecho de las personas transexuales a la integridad física, dejando de considerar la transexualidad una enfermedad mental. Por último, el Parlamento pedía una revisión de la Decisión marco vigente acerca de la lucha contra determinadas formas y manifestaciones de racismo y xenofobia por medio del derecho penal, incluyendo los crímenes de odio y la incitación al odio por motivos de orientación sexual y de identidad de género.

Es evidente que el Parlamento europeo contrastó la homofobia y el racismo sexual, pues esta medida forma parte de la acción de la Unión en tema de derechos fundamentales ${ }^{8}$.

La decisión prevé una consideración general: en Europa, de acuerdo con la más importante investigación sobre el tema realizada por la Agencia de Derechos Fundamentales (FRA), una de cada tres personas LGBT ha sido discriminada a la hora de acceder a bienes y servicios; una de cada cuatro ha sufrido violencia física; una de cada cinco ha sido discriminada en la búsqueda del trabajo o trabajando.

Las distintas medidas ya no parecen suficientes para contrarrestar esta situación: es necesario, pues, que todas las áreas de competencia de la UE fomenten la integración. El Parlamento quiso innovarlo todo desde el principio. Muy interesante es la referencia a la intersexualidad, como grupo independiente que necesita protección como las personas LGBT pero que la Unión y los Estados de la Unión siguen desatendiendo.

En este sentido, la Resolución de la Comisión europea pide que se indique claramente que todo lo que atañe a la intersexualidad se acoge en la Directiva 2006/54 relativa a la igualdad de género en el empleo 9 .

Es necesaria la fuerza impulsora del Parlamento Europeo para el desarrollo de una Europa realmente basada "en los principios de libertad, democracia, respeto de los derechos humanos y las libertades fundamentales [...], como están garantizados en el Convenio Europeo para la Protección de los Derechos Humanos y de las Libertades

8. M. Winkler, "La Cassazione e le famiglie ricomposte: il caso del genitore convivente con persona dello stesso sesso", en Giur.it, 5, 2013.

9. DIRECTIVA 2006/54/CE del Parlamento Europeo y del Consejo del 5 de julio de 2006 sobre la aplicación del principio de igualdad de oportunidades y de trato entre hombres y mujeres en materia de empleo y ocupación. 
Fundamentales [...] y tal como resultan de las tradiciones constitucionales comunes a los Estados miembros" (art. 6 del Tratado de la Unión Europea). Sin embargo, incluso esta estrategia y los resultados esperados estarán afectados por la división de competencias entre la UE y los Estados miembros: la plena igualdad deriva de las reformas que los Estados vayan a tomar, para que haya una Europa "ideal" de veras.

\section{La disciplina italiana: Constitución y Código Civil y el paradigma heterosexual del matrimonio}

En el ordenamiento jurídico italiano la diversidad de sexo de la pareja se requiere por ley para la identificabilidad legal del matrimonio.

Hasta ahora, el sistema legal italiano reconoce en el matrimonio un solo acto relevante por la Ley: el consentimiento que, conformemente a los procedimientos establecidos para la celebración del matrimonio, dos personas de distinto sexo se intercambian, diciendo que desean tomarse por marido y mujer ${ }^{10}$.

En Italia, el matrimonio solo se concibe entre el hombre y la mujer. En el Código Civil -en la parte que se ocupa de las condiciones necesarias para el matrimonio y su celebración, así como para las problemáticas de la filiación, las normas especiales sobre la terminación de los efectos civiles del matrimonio, la disciplina constitucional, en particular los art. 29 y 30 de la Constitución ${ }^{11}$, la disciplina nacional, internacional y comunitaria, en la parte que deja a cada legislación nacional la decisión relativa al matrimonio entre personas del mismo sexo- se destaca que, en el sistema italiano, solo hay matrimonio entre un hombre y una mujer.

En la base de esta conclusión mucha parte de la doctrina subraya que no hay una exclusión lógica o una elección ideológica, sino solo una mera elección positiva que, no obstante se considere anacrónica e inadecuada a la contemporaneidad, sin embargo,

10. Art. 107 del Código Civil italiano: "En el día indicado por las partes el registrador, en presencia de dos testigos, aunque los familiares, lee a los cónyuges los artículos 143, 144 y 147; recibe por cada parte personalmente, una tras otra, la declaración que ellas quieren tomarse, respectivamente, por marido y mujer, y enseguida,declara que ellas están casadas. El certificado de matrimonio debe ser completado inmediatamente después de la celebración".

11. Art. 29 de la Constitución italiana: "La República reconoce los derechos de la familia como sociedad natural fundada en el matrimonio. El matrimonio se basa en la igualdad moral y jurídica de los cónyuges dentro de los límites establecidos por la ley para garantizar la unidad familiar". Art. 30: "Los padres tienen el derecho y el deber de mantener, criar y educar a sus hijos, incluso a aquellos nacidos fuera del matrimonio. En los casos de incapacidad de los padres, la ley prevé que ellos cumplan con sus tareas. La ley garantizará a los hijos nacidos fuera del matrimonio protección jurídica y social, compatible con los derechos de los miembros de la familia legítima. La ley establece las normas y limitaciones para determinar la paternidad". 
no puede ser superada sobre la base del principio de igualdad, porque necesita de una enmienda constitucional específica. En otras palabras, el enemigo del matrimonio entre personas del mismo sexo sigue siendo el art. 29 y, parcialmente, el art. 30 de la Constitución, en el sentido de la opción política y legislativa que las disposiciones de la ley siguen conservando y expresando ${ }^{12}$.

Hoy día, en Italia falta una disciplina legislativa acerca de la convivencia. Rechazadas las propuestas para crear institutos de tipo familiar distintos del modelo tradicional de matrimonio, hay acuerdos de convivencia de tipo contractual que producen efectos entre las partes y los terceros en virtud de la inscripción en los registros públicos. En 2002, en Italia se presentó un proyecto de ley sobre los pactos civiles de solidaridad y uniones de hecho, que implicaba una distinción entre los PACS como uniones civiles de tipo contractual que regulan las relaciones personales y patrimoniales entre personas de sexo igual y diferente, y las uniones de hecho consideradas estables de convivencia entre dos personas de sexo igual o diferente ${ }^{13}$.

Posteriormente, en 2007, se presentó un proyecto de ley sobre el tema del reconocimiento legal de derechos a las personas que viven permanentemente juntos y que, sin ninguna distinción relativa a la orientación sexual, proporcionaría un beneficio para toda persona que comparta una relación amorosa de asistencia mutua material y moral, también por lo que afecta a los alimentos y a los derechos sucesorios.

\section{El Tribunal Constitucional y las decisiones de la Corte Suprema de Casación}

En Italia no existe una disciplina orgánica de la convivencia fuera del matrimonio. El primer dato cierto es la sentencia del Tribunal Constitucional n. 138 del 14 de abril de 2010, cuyos principios fueron reafirmados, poco después, por la Orden n. 276 del 22 de septiembre de 2010. En su primera decisión acerca de la cuestión homosexual, el Tribunal Constitucional italiano afirmó la importancia constitucional de las uniones homosexuales, considerándolas formaciones sociales que, en la

12. V. Barba, "Artificialità del matrimonio e vincoli costituzionali: il caso del matrimonio costituzionale", en Famiglia e diritto, n.10, 2014.

13. A. Scalisi, "Gli obiter dicta della Cassazione, tutti contenuti in una stessa sentenza, in tema di danno esistenziale di danno tanatologico e di cc.dd. Pacs", en La responsabilità civile, n. 1, 2007; M. Gattuso, "Orientamento sessuale, famiglia, eguaglianza”, en La nuova giur.civ.comm., n.12, 2011; F. Chiovini, "Omogenitorialità, margine di apprezzamento, interesse del minore: l'instabile bilanciamento dei giudici di Strasburgo", en La nuova giur.civ.comm., n.11, 2012; T. Auletta, "Ammissibilità nell'ordinamento vigente del matrimonio tra persone del medesimo sesso", en Nuova giur.civ.comm., 7-8, 2015. 
base del art. 2 de la Constitución italiana, necesitan protección con acciones de tipo inmediato ${ }^{14}$.

Este juicio no solo aclara inequívocamente el estatuto jurídico de las parejas homosexuales por lo que al matrimonio se refiere, sino también contiene informaciones muy importantes acerca de la disciplina de la homosexualidad en diferentes situaciones.

Esto ha sido el blanco de todas críticas por parte de las organizaciones que tutelan los derechos homosexuales, que lo consideraron un "paso atrás" en el itinerario hacia mayores conquistas porque aclara la imposibilidad de extender a las parejas homosexuales la disciplina matrimonial.

En realidad, los Tribunales que habían remitido a la Corte la cuestión de constitucionalidad consideraron que las reglas del Código Civil italiano sobre el matrimonio, a pesar de no definir explícitamente la heterosexualidad de los cónyuges, construían el matrimonio en la base del diferente sexo de la pareja ${ }^{15}$.

En particular, el Tribunal de Venecia aclaró que

non si può ignorare il rapido trasformarsi della società e dei costumi avvenuto negli ultimi decenni, nel corso dei quali si è assistito ai superamento del monopolio detenuto dal modello di famiglia normale, tradizionale e al contestuale sorgere spontaneo di forme diverse, seppur minoritarie, di convivenza, che chiedono protezione, si ispirano al modello tradizionale e come quello mirano ad essere considerate e disciplinate. Nuovi bisogni, legati anche all'evoluzione della cultura e della civiltà, chiedono tutela, imponendo un'attenta meditazione sulla persistente compatibilità dell'interpretazione tradizionale con i principi costituzionali.

14. M. Gattuso, "La Corte costituzionale sul matrimonio tra persone dello stesso sesso", en Famiglia e diritto, n.7, 2010, p. 657. El autor aclara que "La Consulta appare in ciò certamente consapevole delle frequentissime sollecitazioni provenienti dal Parlamento di Strasburgo, oltre che del complessivo quadro di riferimento normativo e politico europeo, ove l'isolamento delle posizioni italiane è ormai vistoso".

15. Ord. Tribunal Venecia, 3 de abril de 2009, sez. III sobre el reconocimiento del derecho de los homosexuales a casarse con personas del mismo sexo. El Tribunal afirma que "Nel nostro sistema il matrimonio tra persone dello stesso sesso non è né previsto, né vietato espressamente. Ė certo tuttavia che né il legislatore del 1942, né quello riformatore del 1975 si sono posti la questione del matrimonio omosessuale, all'epoca ancora non dibattuta, almeno nel nostro Paese. Pur non esistendo una norma definitoria espressa, l'istituto del matrimonio, così come previsto nell'attuale ordinamento italiano, si riferisce indiscutibilmente solo al matrimonio tra persone di sesso diverso. Se è vero che il codice civile non indica espressamente la differenza di sesso fra i requisiti per contrarre matrimonio, diverse sue norme, fra cui quelle menzionate nel ricorso e sospettate d'incostituzionalità, si riferiscono al marito e alla moglie come 'attori' della celebrazione (107 e 108), protagonisti del rapporto coniugale (artt. 143 e ss.) e autori della generazione (artt. 231 e ss.). Reputa il Tribunale che, proprio per il chiaro tenore delle norme sopra indicate, non sia possibile - allo stato della normativa vigente - operare un'estensione dell'istituto del matrimonio anche a persone dello stesso sesso. Si tratterebbe di una forzatura non consentita ai giudici (diversi da quello costituzionale), a fronte di una consolidata e ultramillenaria nozione di matrimonio come unione di un uomo e di una donna". Lo mismo fue afirmado en la ord. Corte de Apelación de Trento, el 29 de julio de 2009. 
Sin embargo, los jueces afirmaron que "Un'ulteriore giustificazione per negare il matrimonio omosessuale è spesso individuata nel disposto dell'art. $29,1^{\circ}$ comma della Costituzione, laddove si afferma che la Repubblica riconosce i diritti della famiglia come 'società naturale fondata sul matrimonio', essendosi ritenuto che con tale espressione sì sia inteso tutelare il solo nucleo legittimo di carattere tradizionale, ossia l'unione di un uomo ed una donna suggellata dal vincolo giuridico del matrimonio".

El Tribunal Constitucional rechazó estas aserciones diciendo que el derecho de solicitar una interpretación evolutiva de la disposición constitucional no puede llegar a afectar el núcleo de la ley, y que en este caso no sería una simple interpretación del sistema, sino algo más creativo.

Sin embargo, después de haberse detenido en los arts. 12 y 9 CEDH y de la Carta de Niza, aquellos dedicados específicamente al derecho a casarse y crear una familia, el Tribunal Constitucional ha observado que la legislación no impone, en realidad, la plena igualdad a las uniones homosexuales con las normas establecidas para las uniones homosexuales. Además, las dos disposiciones en cuestión devuelven a las leyes nacionales la disciplina de los procedimientos concretos para el ejercicio del derecho a contraer matrimonio. Así que la cuestión es confiada "a la discreción del Parlamento", con el resultado de que la quaestio sub judice es inaceptable, ya que trató lograr un juicio aditivo que no parece constitucionalmente exigido.

Esta sentencia también es importante en otro punto: el Tribunal precisa que la unión homosexual es una de las "formaciones sociales" previstas en el art. 2 de la Constitución italiana a las que se debe "el reconocimiento jurídico con los derechos y deberes".

Para el Tribunal constitucional es un error pensar que esta protección necesariamente debe reflejarse en la disciplina del matrimonio, mientras que es el "Parlamento quien debe identificar los tipos de garantía y de reconocimiento". Diferentes son los itinerarios para reglamentar este fenómeno. Sin embargo, "es posible que en determinados casos se necesite un tratamiento legal uniforme entre la condición de los esposos y la de las parejas del mismo sexo".

El Tribunal rechaza la ampliación de las normas del matrimonio, pero no rehúye de una posible homogeneidad para toda convivencia fuera del matrimonio, parejas homosexuales o heterosexuales. De hecho, afirma que puede haber casos en que la disciplina del matrimonio se extienda a todos los que viven juntos como marido y mujer, tanto homosexuales como heterosexuales. 
En el mismo sentido, en 2012, el Tribunal de Casación italiano ${ }^{16}$ aplicó los principios afirmados por la Corte Constitucional italiana.

Para la Corte, el matrimonio civil entre personas del mismo sexo, que se celebra en el extranjero, en el ordenamiento jurídico italiano existe, pero solo produce efectos jurídicos; de conformidad con el art. 12 de la Convención Europea de Derechos Humanos y en la base de la interpretación del Tribunal de Estrasburgo ${ }^{17}$, la Corte ha declarado que los miembros de la pareja homosexual, que viven juntos de forma estable, poseyendo el derecho a la 'vida familiar', pueden acudir a la justicia ordinaria para que, en determinadas circunstancias, se cumpla el requisito del tratamiento uniforme previsto por la ley para las parejas casadas ${ }^{18}$.

\section{La propuesta de Ley Cirinnà y el debate en la sociedad civil}

La propuesta de ley Cirinnà se titula "La reglamentación de las uniones civiles entre personas del mismo sexo y la disciplina de la convivencia".

El texto unificado Cirinnà sigue siendo la opción del legislador italiano, respaldado por ahora por la jurisprudencia de la Corte Constitucional, para la institución del matrimonio de las parejas de distinto sexo, creando para las del mismo sexo un nuevo instituto jurídico diferente del matrimonio. Una parte de la doctrina considera que esta solución no es correcta, y que es incluso ilegal.

En esta Ley no se hallan las normas relativas a la denominación ("matrimonio") o que tienen un mayor valor simbólico (amonestaciones, los ritos de celebración, etc.) o que se refieren principalmente a su naturaleza heterosexual (presunción de la concepción). Por lo tanto, existe una equivalencia bajo el perfil simbólico e ideológico entre las dos instituciones, que son diferentes por nombre (matrimonio/unión civil), naturaleza (art. 29 de la Constitución para el matrimonio/art.2 de la Constitución para la unión civil) y premisas (diversidad/identidad sexo). La constitución de la unión civil se da con normas ad hoc.

\footnotetext{
16. Cas., 15 de marzo de 2012, n. 4184. El caso en cuestión se refiere a unos ciudadanos italianos del mismo sexo que, casándose en los Países Bajos, habían desafiado la negativa de la transcripción del acto, con la oposición del registrador italiano; la SC ha corregido la motivación del decreto de la Audiencia Territorial, que había legitimado la negativa de la transcripción del acto por ausencia de su "capacidad de configuración como el matrimonio".

17. Sentencia de 24 de junio de 2010, Schalk y Kopf v. Austria.

18. A. Rossolillo, "Registered partnership e matrimoni tra persone dello stesso sesso: problemi di qualificazione ed effetti nell'ordinamento italiano", en Riv. dir. int. priv. proc., 2003, p. 380.
} 
Se ha excluido la presunción de la concepción, pero permanece la adopción en casos especiales: el texto extiende la llamada stepchild adoption, a saber, la adopción del niño que vive en una pareja del mismo sexo, pero que es el hijo biológico de uno de los dos, prevista en el art. 44 de la ley sobre adopciones ${ }^{19}$. No hay cambios en el texto de la inseminación artificial.

Se desatiende la cuestión relativa a la transcripción de las actas de nacimiento extranjeras y de adopciones realizadas en el extranjero, por lo que la jurisprudencia tiene que seguir desarrollándose.

No se citan las normas del Código Civil de manera indiscriminada, sino solo respecto de las cuestiones sin valor simbólico relacionadas con la regulación de las relaciones personales y patrimoniales, la sucesión, la nulidad, la disolución del matrimonio (art. 3, párrafo I y II, arts. 4, 6). Esta Ley pareció extender a las parejas de gays y lesbianas mucha parte de la ley de matrimonio: sin embargo, se puede notar que estas normas solo se mencionan, pero no se preveen cambios en el Código Civil, probablemente para tranquilizar a la parte tradicionalista y conservadora del Parlamento.

La única excepción (art. 2 que modifica el art. $86 \mathrm{cc}$ ) se impone por la razonable necesidad de garantizar que una persona civilmente unida con otra de su mismo sexo pueda casarse con personas de diferente sexo.

Las otras reglas, no previstas en el Código Civil, en relación con los derechos sociales, la salud, el derecho penitenciario, los impuestos, la seguridad social, procesal, penal, se acuerdan de forma indiscriminada (art. 3, párrafo III), previendo una modificación directa de las mismas ${ }^{20}$ puesto que carecen de valor simbólico y porque la jurisprudencia europea no permite discriminar en materia de derechos sociales ${ }^{21}$.

Sobre la existencia de la dotación financiera para la ley de uniones civiles, el 23 de julio de 2015 fue firmado por el Contador General del Estado del Ministerio de Economía y Hacienda el informe técnico que admite la posibilidad de financiación.

\footnotetext{
19. La adopción en casos específicos está regulada por el art. 44 de la Ley no. 184/83, sustituido por la Ley no. 149/2001, y protege, en las dos primeras letras, la relación que se crea cuando se coloca un niño en una familia en la cual ya ha desarrollado previamente vínculos emocionales, mientras en las otras dos, los niños que se encuentran en particulares situaciones de incomodidad. Las circunstancias en las que pueden recurrir a este tipo de organización están estrictamente prescritas por la ley y, por lo general, con algunas excepciones, los adoptados añaden a su apellido aquel de quien adopta, y esto ocurre solo si los padres del adoptado lo permiten.

20. Modificación posible con delegación al gobierno: véase el art. 7, párrafo I, letra c).

21. Cabe destacar que no se puede evitar que se extienda, por ejemplo, la pensión de sobrevivencia a las uniones civiles, ya que fue permitido por el Tribunal de Justicia (Tribunal de Justicia de la Unión Europea, Sala principal, sentencia del 1 de abril de 2008, debido a C-267/06 Tadao Maruko v. Versorgungsanstalt der Deutschen Buhnen).
} 


\section{La condena de Italia por la CEDH por violar el derecho a la vida privada y familiar de gays, lesbianas y bisexuales}

$\mathrm{Al}$ no haber reconocido o protegido las parejas del mismo sexo, al menos a través de la institución de uniones civiles o parejas de hecho registradas, la República Italiana ha violado el derecho al respeto de la vida privada y familiar.

El 21 de julio de 2015, la Corte Europea de Derechos Humanos reconoció la violación del Estado italiano del derecho a la vida privada y familiar (art. 8 de la Convención) de la comunidad de gays, lesbianas y bisexuales, y lo condenó a indemnizar a los demandantes los daños y perjuicios por $€ 5.000,00$.

Preliminarmente, la Corte recordó que ya había declarado que las parejas homosexuales, como las heterosexuales, pueden tener relaciones estables y que, además, coinciden bastante con la pareja heterosexual por lo que a la necesidad de reconocimiento y protección jurídica de su relación se refiere.

La Corte también reconoce que las parejas del mismo sexo son protegidas por un régimen que garantiza la protección a la 'vida familiar'.

Por otra parte, se señala que "a pesar de algunos intentos a lo largo de tres décadas, el legislador italiano no ha sabido aprobar su legislación”, aunque en el Tribunal Constitucional italiano y el Tribunal Supremo ya varias veces se había producido una lesión de la Constitución italiana (art. 2) y pedido la intervención del Parlamento.

Referente al art. 8 de la CEDH, la Corte afirma que "los Estados gozan de un margen de apreciación en el cumplimiento de sus obligaciones positivas. Al determinar el alcance de ese margen deben considerarse ciertos factores. En el contexto de la vida privada, la Corte sostuvo que cuando está en juego un aspecto particularmente importante para la existencia y/o la identidad de una persona, el margen individual concedido al Estado está restringido" 22 .

Cuando hay consenso en los Estados miembros del Consejo de Europa -por la importancia de los intereses en juego, o de los mejores medios para protegerla, en particular cuando el caso plantea cuestiones moral y políticamente delicadas- el margen es necesariamente más amplio ${ }^{23}$.

\footnotetext{
22. En la sentencia Pretty v. The United Kingdom, no. 2346/02, la Corte EDU le negó a Diane Pretty la impunidad pedida para su marido, que la asistía para ayudarla a morir. La mujer inglesa, que sufría una enfermedad neurodegenerativa grave, estaba paralizada del cuello para abajo, respiraba con dificultad, perdió toda capacidad de expresión y era alimentada por una sonda nasogástrica. Su esperanza de vida era muy breve, unas pocas semanas o tal vez un par de meses, pero su conciencia no quedó afectada.

23. V. $X, Y$ and $Z$ v. the United Kingdom, 22 de abril de 1997, $\$ 44$, Reports 1997-II; Fretté v. France, no. 36515/97, $\$ 41$, ECHR 2002-I; y Christine Goodwin, $\$ 85$.
} 
El caso involucra a tres parejas italianas según las cuales la imposibilidad de contraer matrimonio en el sistema italiano, por la ausencia de una legislación sobre uniones del mismo sexo, viola la CEDH. La decisión condena a Italia y la obliga a adoptar una legislación que reconozca y reglamente los matrimonios de personas del mismo sexo. Como se ha dicho, la Corte de Derechos Humanos establece que el contenido fundamental del art. 8 de la $\mathrm{CEDH}$ (derecho al respeto de la vida privada y familiar) protege las personas contra las interferencias injustificadas de las autoridades públicas. Sin embargo, el acuerdo también incluye "obligaciones positivas", destinadas a la realización del derecho al respeto de la vida familiar. Por lo tanto, los Estados miembros tal vez tengan que tomar medidas destinadas a garantizar el respeto de la vida familiar, también en el ámbito de las relaciones entre los individuos.

La Corte señala que, en este caso, al no poder contraer matrimonio, los demandantes no han tenido la oportunidad de acceder a un marco jurídico específico como el de las uniones civiles o parejas de hecho registradas, que les garantizara los derechos correspondientes a una pareja que tiene una relación de largo plazo.

Si existe un "conflict between the social reality of the applicants, who for the most part live their relationship openly in Italy, and the law, which gives them no official recognition on the territory" el Parlamento está llamado a responder a un social need, así como a la necesidad de la pareja del mismo sexo de lograr algo concreto que, en ausencia de matrimonio, puede garantizar de alguna manera sus derechos (párrafos 173-174).

En la base de dichos intereses "individuales", la Corte EDU contrarrestaría fácilmente los argumentos propuestos por el Gobierno italiano basados, fundamentalmente, en otorgarles la facultad a los Estados europeos de introducir una forma alternativa de matrimonio cuando la sociedad civil esté lista para este cambio. Por tanto, los jueces no consideran importante el margen de apreciación reconocido hasta ahora al tema, ya que no se trata de un derecho específico o adicional que puede o no puede ser atribuido a la pareja del mismo sexo. Sin embargo, se trata del derecho más general para el reconocimiento legal que los Estados Partes, en virtud del mismo margen de apreciación, pueden poner en práctica de varias formas, esto es, otorgando el estatus más adecuado dependiendo de las sensibilidades nacionales.

Así que la decisión Oliari es un paso muy importante hacia el reconocimiento de las uniones del mismo sexo en Europa. 


\section{La importancia de discutir acerca de relaciones afectivas y de vida privada}

En el pensamiento jurídico a menudo se percibe la impermeabilidad de un enfoque que no se detiene detrás de la supuesta neutralidad del conocimiento. Sin embargo, las experiencias jurídicas no pueden ser relegadas al mundo de las simulaciones, sino hay que dejarlas en la realidad social.

Las leyes son un espejo de la sociedad y guían los comportamientos: pues, son el resultado de la dinámica social y un factor de desarrollo. En su mayoría, las leyes traducen los principios. En un estado de derecho secular las leyes deben proteger los derechos fundamentales de las personas, antes que todo la igual dignidad.

En el ámbito del derecho, el análisis de la diferencia sexual tiene naturaleza e itinerarios diferentes: está inspirado en un lenguaje pobre, opción que no está exenta de implicaciones ideológicas.

Esforzándose para construir categorías y normas simplificadas, con la finalidad de reducir la realidad a esquemas comprensibles y normalizados, a veces la ley ha desatendido la complejidad de los fenómenos y de las historias de todas aquellas personas que expresan su identidad de género en formas no "tradicionales", esto es, de manera personal, y no directamente asociadas con las categorías de sexo y género. Estas personas, pues, están de tránsito, en movimiento, tratando de romper las fronteras entre los géneros, exigiendo el respeto de la individualidad y de las particularidades de las personas.

El tema de la identidad sexual es un punto "panorámico" para estudiar los cambios sociales, pero también es el lugar en que más difícilmente se encuentran soluciones que comunican con las reglas y no solo se oponen a ellas.

Explorar la pertinencia y la multiplicidad de la diferencia sexual en la ley significa mirar el "significado" de los derechos y su impacto en la construcción legal y simbólica del género, el reconocimiento de la identidad de género y su construcción en términos de subordinación a través del lenguaje y de los conceptos jurídicos, la supuesta neutralidad de las normas de derecho privado respecto de las desigualdades que originan de esta neutralidad, la separación preconcebida de las diferentes áreas de la ley que están afectadas por las relaciones de género -trabajo, familia, derechos contractuales la persona, responsabilidad civil-y su interacción en la producción de la estructura de distribución actual en términos de recursos y poder social.

La propuesta de Ley que quiere disciplinar las uniones civiles no señala la falta de distinción entre parejas homosexuales y heterosexuales. Básicamente la propuesta no 
propone una alternativa viable para el matrimonio que se extendería a todos los derechos civiles de los que una pareja casada puede gozar.

Por esta razón, el debate -dentro y fuera del Parlamento- no puede pararse, sino debe seguir el camino de la dignidad de la persona, en el pleno respeto del mensaje de la Constitución italiana. 